\title{
MONITORING AND CONTROL OF REFRACTORY WEAR FOR INTENSIVE OPERATION OF BLAST FURNACE*
}

\author{
Afshin Sadri \\ S. Filatov ${ }^{1}$ \\ I. Kurunov ${ }^{1}$ \\ Y. Gordon ${ }^{2}$ \\ W. L. Ying ${ }^{2}$ \\ J. Erskine ${ }^{2}$
}

\begin{abstract}
One of the main reasons for blast furnace reline is the loss of refractory lining, particularly in the hearth and taphole regions. Intense operation of the blast furnace can result in extensive refractory wear and deterioration. This can then affect the continuity of the operation and the furnace campaign life. Novo-Lipetsk (NLMK) and Hatch developed a systematic approach to monitor the condition of blast furnace hearth linings using Acousto Ultrasonic-Echo (AU-E), a non-destructive testing system developed by Hatch. Continuous and periodic inspections of blast furnaces revealed areas with accelerated refractory deterioration, formation of elephant foot, extent and speed of refractory wear, as well as cracks and other anomalies. Improvement in coke quality, stave washing, the addition of titania, and other changes were recommended and implemented to prolong furnace life while maintaining the intensity of furnace operation. This paper demonstrates how the coordinated efforts between NLMK and Hatch resulted in prolonging the blast furnace campaign life.

Keywords: Blast furnace inspection and monitoring; Non-Destructive Testing (NDT); Refractory deterioration; Blast furnace campaign
\end{abstract}




\section{INTRODUCTION}

Intensive operation of a blast furnace (BF) can offer many benefits, including an increase in production of hot metal and profitability of iron and steel operations. However, intensive operation can also increase the rate of refractory wear and compromise blast furnace structural integrity, particularly if no measures are taken to protect refractory lining and to build stable accretion. This paper outlines how NonDestructive Testing (NDT) was used at NLMK blast furnaces to monitor and reduce refractory wear in the hearth while maintaining intensive operation.

Novo-Lipetsk Metallurgical Combine (NLMK) is a Russian Iron \& Steel giant, producing 12.7 million ton of steel annually. The plant has 5 operational blast furnaces: their design and operating parameters are presented in Table 1:

Table 1. Design and Operating parameters of NLMK's blast furnaces

\begin{tabular}{|c|c|c|c|c|c|}
\hline Paramater & BF 3 & BF 4 & BF 5 & BF 6 & BF 7 \\
\hline Last major reline, month, year & $\begin{array}{l}\text { Sept. } \\
2000\end{array}$ & $\begin{array}{l}\text { May } \\
1999\end{array}$ & $\begin{array}{c}\text { December } 1996 \text { (April } \\
2015 \text { - hearth walls) }\end{array}$ & $\begin{array}{l}\text { July } \\
1993\end{array}$ & $\begin{array}{c}\text { Blow - in } \\
\text { August } 2011\end{array}$ \\
\hline Furnace working volume, $\mathrm{m}^{3}$ & 1,700 & 1,700 & 2,760 & 2,760 & 3,561 \\
\hline Hearth diameter, $\mathrm{m}$ & 10 & 10 & 12 & 12 & 13.1 \\
\hline Metallic burden $\mathrm{Fe}_{\text {total }}$ (fluxed), \% & 57.26 & 57.93 & 56.86 & 58.75 & 57.18 \\
\hline Coke rate, $\mathrm{kg} / \mathrm{thm}$ & 422.8 & 302.7 & 321.3 & 395.2 & 390 \\
\hline PCI rate, $\mathrm{kg} /$ thym & & 134.7 & 120.6 & & \\
\hline Natutral gas rate, $\mathrm{Nm} 3 / \mathrm{thm}$ & 98.3 & 53.1 & 63.1 & 128.2 & 129.9 \\
\hline Oxygen enrichment, $\%$ in blast & 27.48 & 28.13 & 27.1 & 30.22 & 30.86 \\
\hline Blast temperature, ${ }^{0} \mathrm{C}$ & 1,100 & 1,139 & 1,096 & 1,174 & 1.222 \\
\hline Daily production, thm/day & 4,765 & 5,622 & 8,177 & 8,284 & 12,500 \\
\hline Specific productivity, thm $/ \mathrm{m}^{3} /$ day (WV) & 2.8 & 3.31 & 2.99 & 3.03 & 3.51 \\
\hline Spcific productivity, thm/m²/day (hearth $\emptyset$ ) & 60.7 & 71.62 & 72.36 & 73.3 & 92.8 \\
\hline Slag rate, $\mathrm{kg} /$ thm & 389 & 361 & 378 & 333 & 380 \\
\hline
\end{tabular}

Table 1 shows that NLMK blast furnaces operate with comparatively low total iron in fluxed metallic burden, with values in the range of $56.86 \%-58.75 \%$. Additionally, the furnaces operate with high levels of oxygen enrichment $(27.2 \%-30.86 \%)$, moderate rates of coke and supplemental fuels, and blast temperatures above 1,100 0C. Despite the low total iron in a metallic burden and high slag volume, the smelting process is quite intensive with specific productivity ranging from $60.7 \mathrm{thm} / \mathrm{m} 2 /$ day $(2.8$ thm/m3/day) for BF \#3 and 92.8 thm/m2/day (3.51 thm/m3/day) for BF \#7.

Out of the 5 blast furnaces, furnace \#6 is the oldest in service at a 23 year campaign life and furnace \#7 is the newest (5 year service life). The service lives of blast furnaces \#3, 4, and 5 are 16, 17 and 20 years respectively. Intensive operation of blast furnaces, especially the older furnaces (\#3-6), requires careful monitoring of refractory lining conditions in the furnace hearth. This monitoring allows for timely preventive measures to retard refractory wear and create a stable protective accretion on the walls of the hearth, preventing chemical and thermal attack by hot metal.

Blast furnaces \#5, 6, and 7 are equipped with embedded thermocouple. Furnaces \#6 and 7 have thermal models to estimate the remaining lining profile (thickness of refractory plus accretion). However, over time many thermocouples have been damaged, leaving few or no thermocouples in a given area. Blast furnaces \#3 and 4 are without any thermocouples. This lack of information makes the estimation of refractory wear and accretion extent difficult. 
In 2013 NLMK engaged Hatch for non-destructive testing of the NLMK blast furnaces using Hatch's patented Acousto Ultrasonic - Echo (AU-E) technology [1]. NLMK and Hatch developed a systematic approach to monitor the condition of blast furnace hearth linings. This approach involves quarterly and semiannual inspections of the older blast furnaces (\#5 and 6) and the newest BF (\#7). Additionally, annual inspections of the hearths of the other blast furnaces were conducted. Results of each inspection are thoroughly discussed with plant management and operators, and subsequent measures were implemented to retard or stop further refractory deterioration and to prolong blast furnace campaign lives.

\section{AU-E METHOD OF NON-DESTRUCTIVE REFRACTORY TESTING}

Acousto Ultrasonic Echo (AU-E) is a stress wave propagation technique capable of measuring the thickness of refractory layers and build-up material. AU-E uses time and frequency data analysis to determine refractory thickness and detect anomalies such as cracks, gaps or metal penetration within the refractory lining. During the measurement, a mechanical impact on the surface of the structure generates a stress pulse, which propagates into the refractory layers. The wave is partially reflected by the change in material properties of each layer of the refractory lining, but also propagates through the solid refractory layers up to a brick/brick, brick/gas, or brick/molten metal interface. The compressive waves (or P-waves) are collected by a receiver and the signals are analyzed for refractory quality and thickness assessment.

The main details of the AU-E method are presented in this paper. A more detailed description of the AU-E method is presented in several other papers [2 -4].
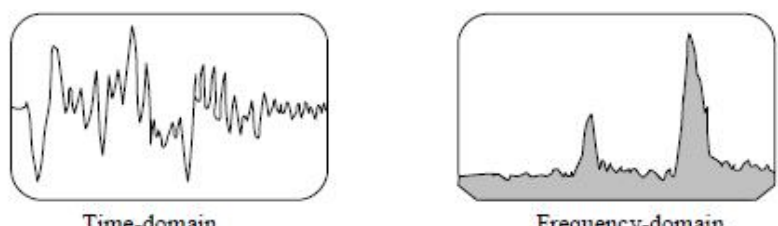

Refractory wall thickness

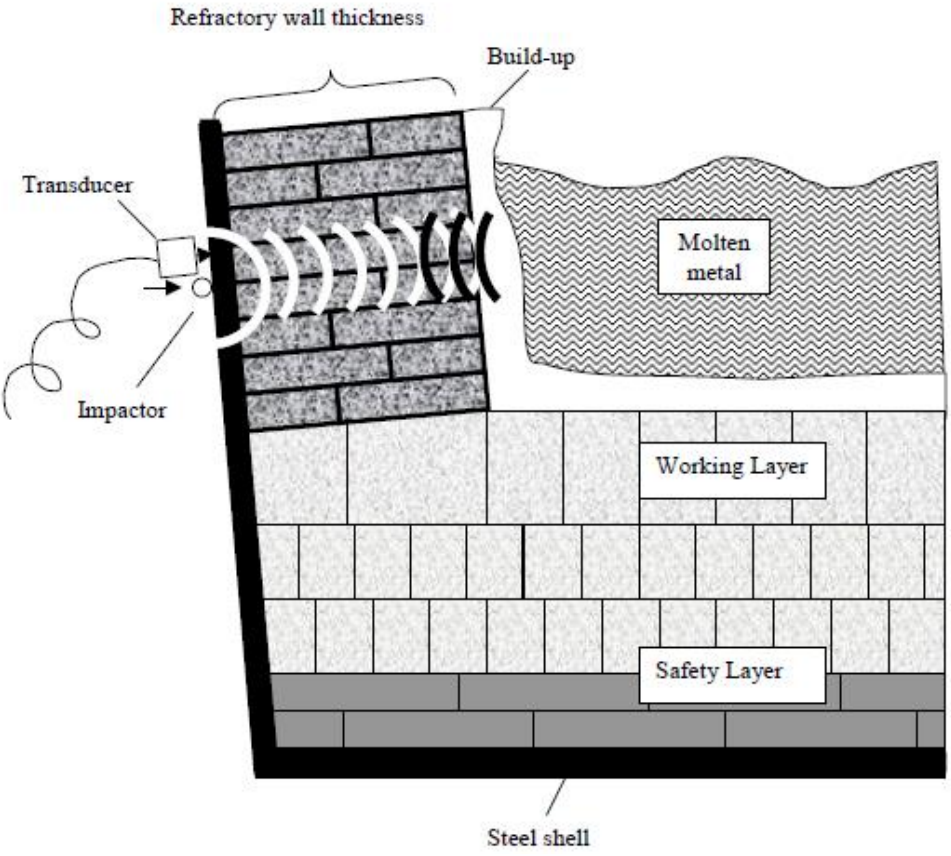

Figure 1. Illustration of AU-E method. 
The field data collected in the time domain is extremely complex, containing numerous frequencies and multiple reflections, diffractions, and refractions from body and surface waves. Converted to the frequency domain, the results are much better defined. A lower reflection frequency corresponds to a greater distance to the signal reflection interface. The distinct peaks in signal amplitude correspond with the boundaries between liquid metal and accretion, accretion and refractory and the locations of anomalies (crack, oxidized carbon etc.) The first distinct amplitude at the lowest frequency is associated with boundary between accretion and hot metal, the second distinct amplitude at higher frequency characterizes the boundary between accretion and refractory, and the third distinct amplitude at the highest frequency would show the position of a crack or anomaly.

The thickness of the layer of material for the AU-E technique is estimated by the following governing equation:

$$
T=\frac{\alpha \beta V_{p}}{2 f_{p}}
$$

Where $T$ is the thickness or depth of the reflecting surface; $f_{p}$ is the P-wave frequency; $V_{p}$ is the propagation speed of $P$-wave in the material; $\alpha$ is the temperature correction factor; $\beta$ is the shape factor.

The shape factor $\beta$, accounts for the reduction in velocity due to various furnace shapes, such as cylindrical or rectangular. For blast furnaces where lateral dimensions are at least six times the thickness of the lining, the $\beta$ factor is 0.96 . The thermal correction factor, $\alpha$ is the ratio of refractory Young's modulus of elasticity under service conditions $\left(E_{x}\right)$ to the modulus of elasticity at room temperature $\left(E_{0}\right)$ : $\alpha=E_{x} / E_{o}$. In most cases it is assumed that the Young's modulus of elasticity of the refractory changes linearly between the hot and cold face as a function of temperature.

For a multilayered section such as a furnace hearth, the thickness of the final refractory layer $\left(T_{n}\right)$ is calculated based on the following equation:

$$
T_{n}=\frac{\left(V_{p}\right)_{n} \alpha_{n} \beta_{n}}{2}\left[\frac{1}{f}-\sum_{i=1}^{n-1} \frac{2 T_{i}}{\left(V_{P}\right)_{i} \alpha_{i} \beta_{i}}\right]
$$

where $\mathrm{n}$ refers to specific layer of the hearth lining; $f$ is the resonance frequency for the thickness of the $\mathrm{n}^{\text {th }}$ layer; i refers to the initial thickness of the layer of refractory. Prior to the collection of field data, the apparent $\mathrm{P}$-wave speed of each brick layer is determined by calibrating representative brick samples at room temperature. The wave speed calibration measurements must be carried out on all the materials through which the wave propagates. The a factor can either be calculated experimentally, by heating brick samples and measuring the wave speeds at the desired temperatures, or it can be calculated by the particular brick's elastic and thermal properties.

If sample bricks are not available (e.g. in the case of NLMK) Hatch uses the information on properties of similar brick received from vendor catalogues or measured during previous projects to estimate apparent $\mathrm{P}$-wave speed. This approximation brings some uncertainties into the accuracy of refractory thickness estimation, which is an integral part of the overall measurement error of $4-7 \%$. The estimation of the thickness of accretion is less accurate (error is approximately 15\%), since the properties of accretion are seldom known and can vary substantially. 


\section{EXAMPLES OF MEASUREMENTS}

Beginning in July 2013, AU-E measurements of the remaining refractory were performed every six months for the hearths of blast furnaces $\# 5$ and 6 . These two furnaces were selected because of their condition and age (20 and 23 years into their campaign lives for blast furnaces \#5 and 6 respectively). Blast furnaces \#5 and 6 combined produce approximately $41-42 \%$ of the overall 37 plus thousand tons of hot metal per day produced at NLMK. Therefore, the stable operation of these two furnaces is critical for success of the entire Iron \& Steel Works.

Typical AU-E results for blast furnace \#5 are presented in Figure 2. It shows the semi-annual testing in November 2013 and July 2014. The estimated remaining refractory profile for July 2014 is shown in blue. Detected build-up is shown in green, and anomalies are shown in red. Anomalies could represent cracks or delaminations within the refractory, or loose castable. For comparison, the remaining refractory profile for November is shown in yellow, clearly showing areas where refractory wear has occurred.

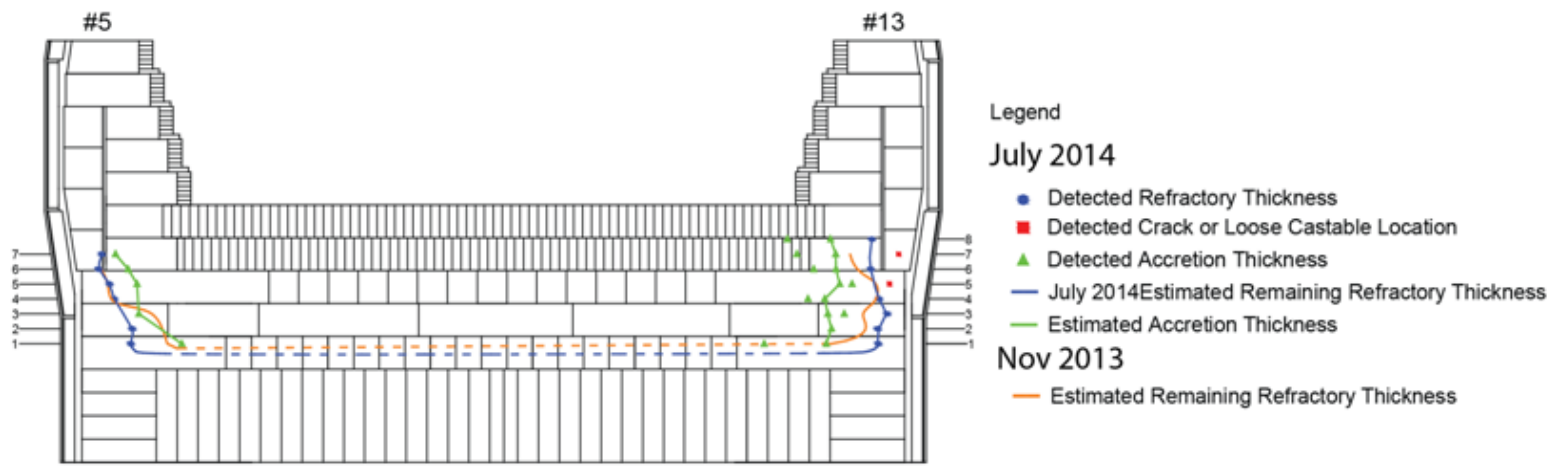

Figure 2. Results of AU-E testing of the hearth of BF \#5 (November 2013 and July 2014).

The test results showed significant increase of wear of the walls of the low hearth over time and the formation of the "elephant foot". Formation of "elephant foot" in the blast furnace sump can be attributed to the conditions of the "dead man" which forms the flow of the metal in the low hearth region. The "dead man" should be floating and permeable for the hot metal to avoid excessive high velocity peripheral flow of the hot metal and erosion of refractory lining.

Based on Figure 2 and the remaining AU-E results, in July 2014 the following conclusions were made for $\mathrm{BF} 5$ :

- First two bottom slab layers of the hearth were worn. The third bottom slab layer was partially worn.

- The average remaining refractory was $700 \mathrm{~mm}$ in July 2014 (original average refractory thickness of $1710 \mathrm{~mm}$ ). This was equivalent to a remaining refractory thickness of $41 \%$. There was a $7 \%$ reduction in remaining thickness since November 2013 (remaining thickness of 48\%).

Figure 3 shows more recent results for blast furnace \#5. The results correspond to the last inspection in February 2015 before the shutdown of the furnace for hearth repair. The estimated remaining refractory profile for February 2015 is shown in blue, while the profile for July 2014 is shown in yellow. The two profiles are much closer together compared to the profiles shown in Figure 2, indicating that the refractory wear was more stable between July 2014 and February 2015. 
Based on Figure 3 and the remaining AU-E results, in February 2015 the following conclusions were made for BF\#5:

- The average remaining refractory was $41 \%$ of the original average refractory thickness of $1710 \mathrm{~mm}$. This was similar to the previous survey in July 2014 (remaining thickness of $41 \%$ ).

- The current NDT result indicated that the TiO2 was effectively charged, and has produced a substantial build-up thickness at the hot face of the refractory. The average accretion extent is about $1440 \mathrm{~mm}$ measured from the cold face of the refractory, which is similar to the previous survey in July 2014 (average of 1460 $\mathrm{mm})$.
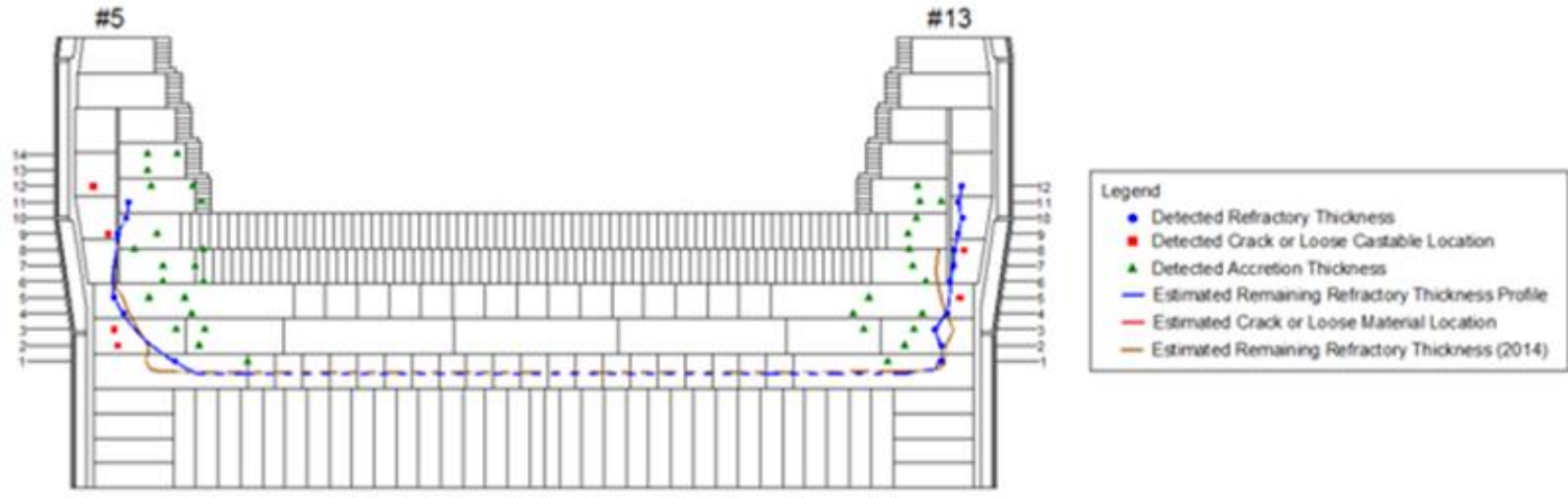

Figure 3. Results of AU-E testing of the hearth of BF \#5 (February 2015).

Blast furnace \#7 "Rossiyanka" was tested twice in February and September 2015. Typical AU-E results for this furnace are presented in Figure 4.
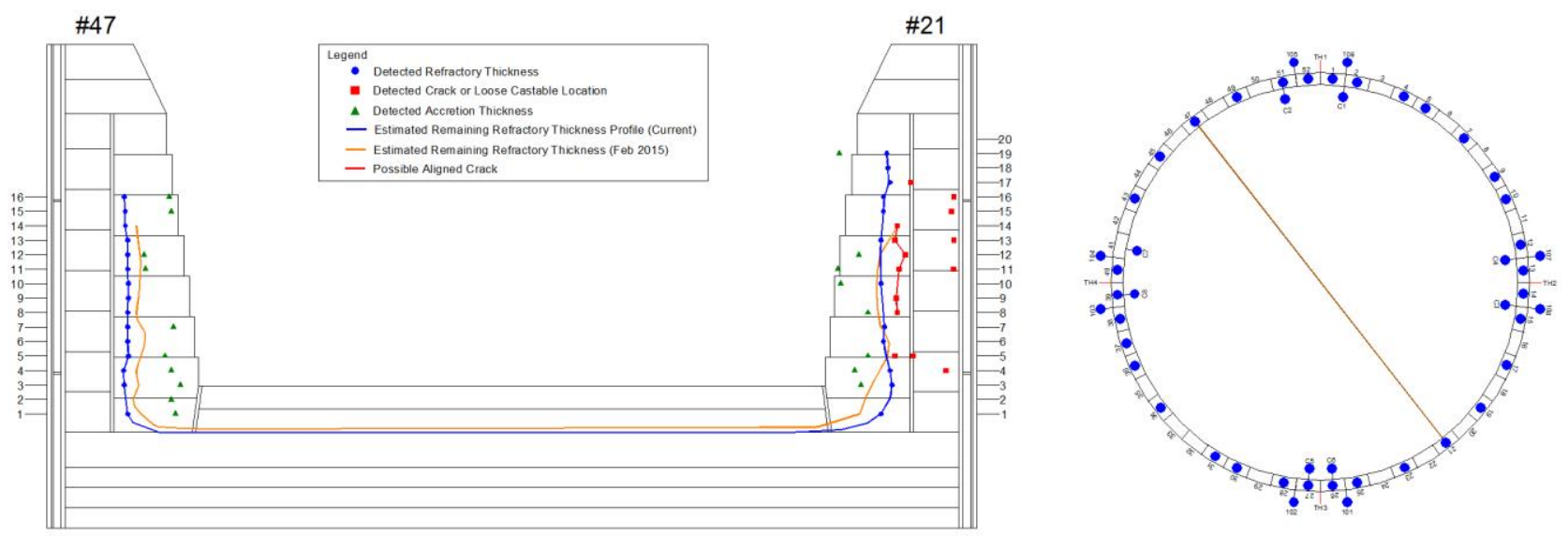

Figure 4. AU-E results for blast furnace \#7 (September 2015).

Results of AU-E measurements of blast furnace \#7 lead to the following conclusions:

- The top two layers of bottom carbon blocks were worn.

- The average remaining refractory thickness of the hearth walls is $1130 \mathrm{~mm}$, $51 \%$ of the average original thickness of $2147 \mathrm{~mm}$. This is an average wear of $13 \%$ since February 2015 (1410 mm, 64\% remaining). Most of the wear has occurred near the taphole region. Further away from the taphole, the wear is significantly less. 
- The minimum detected remaining refractory thickness is 850 to $870 \mathrm{~mm}$. These points correspond to a remaining refractory of $38 \%$ to $40 \%$.

- Test results show the beginning of formation of the "elephant foot" in the sump of BF7.

- Stable accretion of 300 to $1,000 \mathrm{~mm}$ thickness was built along the hearth's refractory lining protecting it from further intensive deterioration

The AU-E results of blast furnace \#7 show that during the four and a half years of operation, the blast furnace hearth side walls lost an average of almost $50 \%$ of its initial refractory thickness. The intensive loss of refractory lining at this furnace most probably happened during first two and a half years of operation, when coke CSR was in the range of $45-55 \%$. The furnace operated with littered "dead man" and hearth, which led to non-stable operation and productivity loss. Starting from 2014 the coke quality was gradually improved to CSR in the range of 62 to 64\%, which enhanced the furnace performance and "dead man" conditions. Addition of shungite and titania created a stable accretion on the hearth walls which protects the refractory lining from further rapid deterioration. The blast furnace can continue its intensive operation while an annual NDT monitoring of the hearth and tap hole level conditions is required for any timely preventive measures.

\section{ACCURACY OF REFRACTORY THICKNESS ESTIMATE}

Blast furnace \#5 was shut down and cooled in March 2015 in preparation for a hearth reline. This provided an opportunity to verify the accuracy of the AU-E measurements. To provide a direct comparison, Hatch performed measurements one week before the blast furnace shutdown. One core sampled was drilled while the furnace was still hot. After the furnace was drained and cooled, physical measurements of the remaining thickness were made by tape measure. These measurements were performed by blast furnace personnel.

The location of the core drill was at level 12, while the physical measurements were taken at level 8 (Figure ). These results were compared to the corresponding AU-E measurements at close proximity.

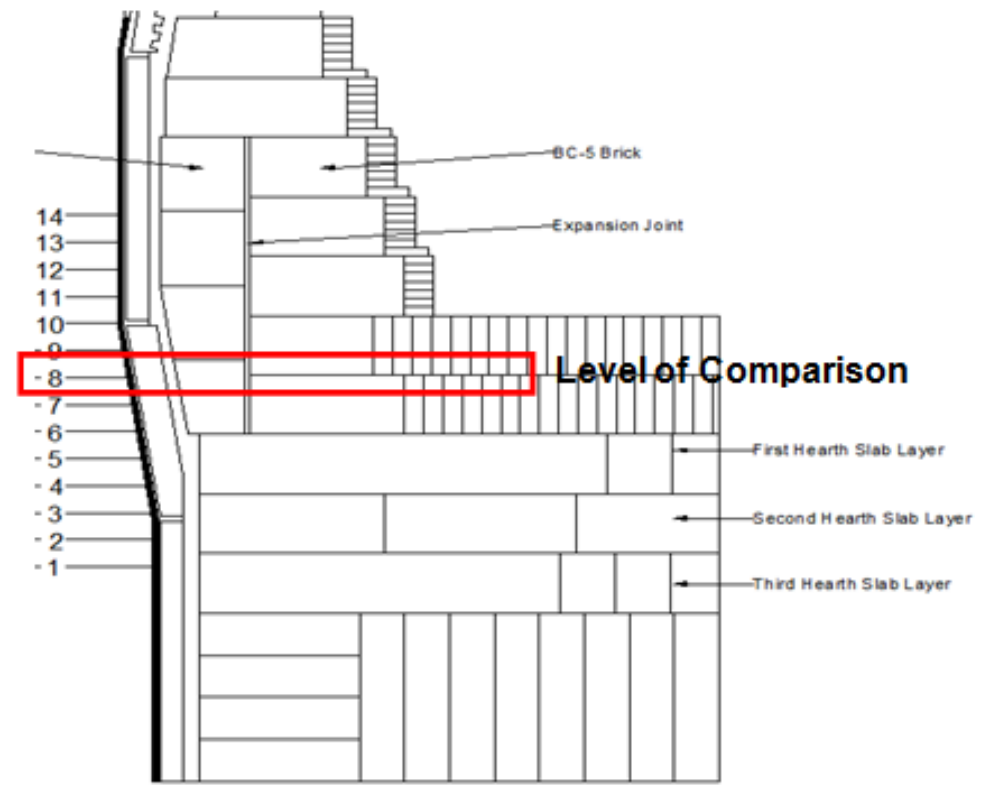

Figure 5. Location of the core drilling and physical measurements. 
The core drill result revealed a remaining refractory thickness of $530 \mathrm{~mm}$ whilst AU-E measurements indicated a refractory thickness of $500 \mathrm{~mm}$. This gives a difference of $6 \%$. The comparison of AU-E results with results of tape measurements are presented in Table 2:

Table 2. Accuracy of AU-E measurements

\begin{tabular}{|l|l|l|l|l|l|l|}
\hline \multirow{2}{*}{ Line } & \multirow{2}{*}{ Level } & \multicolumn{2}{|c|}{$\begin{array}{l}\text { Remaining Refractory Measurement } \\
\text { in February 2015 }(\mathrm{mm})\end{array}$} & \multirow{2}{*}{$\begin{array}{l}\text { Difference, } \\
(+/-\mathrm{mm})\end{array}$} & $\begin{array}{l}\text { Difference, } \\
\% \text { of AU-E }\end{array}$ & Remarks \\
\cline { 3 - 6 } & & $\begin{array}{l}\text { Hatch AU-E } \\
\text { Measurement }\end{array}$ & $\begin{array}{l}\text { Plant Physical Tape } \\
\text { Measurement }\end{array}$ & & & \\
\hline 3 & 8 & 550 & 530 & 20 & 4 & Good correlation \\
\hline 6 & 8 & 780 & 750 & 30 & 4 & Good correlation \\
\hline 9 & 8 & 650 & 600 & 50 & 8 & Good correlation \\
\hline 11 & 8 & 700 & 720 & 20 & 3 & Good correlation \\
\hline 15 & 8 & 570 & 520 & 50 & 9 & Good correlation \\
\hline \multicolumn{2}{|l|}{ Average } & 652 & 607 & 45 & 7 & \\
\hline
\end{tabular}

The differences between the physical measurements and the AU-E measurements range from $20-50 \mathrm{~mm}$. The comparison of the AU-E results and the physical measurements (Table 2) confirmed that AU-E accuracy is about 4 to $7 \%$. The error due to the approximation of the refractory properties is absorbed within this range.

\section{EXTENSION OF BLAST FURNACE CAMPAIGN LIFE}

Hatch and NLMK proposed several strategies to retard refractory deterioration and prolong the furnace campaign and NLMK then implemented these measures. With regular NDT inspections, the state of the refractory was evaluated every 6 months. This allowed the effects of these campaign prolonging measures be measured, tracked, and adjusted as needed, leading to a stabilization of refractory wear in both blast furnaces \#5 and 6.

The measures implemented to retard refractory wear are as follows:

- Addition of shungite to the metallic burden in amount of $35-37 \mathrm{~kg} / \mathrm{thm}$. Shungite is a natural mineral with known deposits only in Karelia, Russia, which consists of $\sim 58-62 \%$ of $\mathrm{SiO} 2$ and $28-32 \%$ of carbon [5]. At temperatures of about $1400{ }^{\circ} \mathrm{C}$, silica and carbon of shungite start to react forming silicon carbide ( $\mathrm{SiC}$ ). $\mathrm{SiC}$ partially reacts with the melted products and partially penetrates into the furnace hearth in a solid form it where precipitates on the walls forming an accretion similar to titania carbides and nitrides.

- Addition of titania containing materials in amount of $7-12 \mathrm{~kg} \mathrm{TiO} 2 /$ thm. TiO2 forms titanium carbide and titania nitrides, which precipitates on a hearth walls.

- Improvement in coke quality from CSR $45-55 \%$ to $63-65 \%$ and reduction in $\mathrm{CRI}-$ from $27-30 \%$ to $23-24 \%$. This improvement allowed for an increased permeability of the "dead man" and a reduced circumferential velocity of hot metal which promotes the formation of "elephant foot".

- Stave washing allows the removal of scale from water pipes, thereby improving the heat transfer efficiency. This helps to create stable accretion.

- Formation of barriers ("tongues") beneath tapholes by using an excessive amount of the mud gun clay to reduce circumferential velocity of hot metal in the sump etc. 
All of these measures allowed for the continuation of the blast furnace campaigns while maintaining intensive operation.

As tracked by the NDT surveys, the trends of refractory deterioration for blast furnaces \#5 and 6 are presented in Figure 6 and Figure .

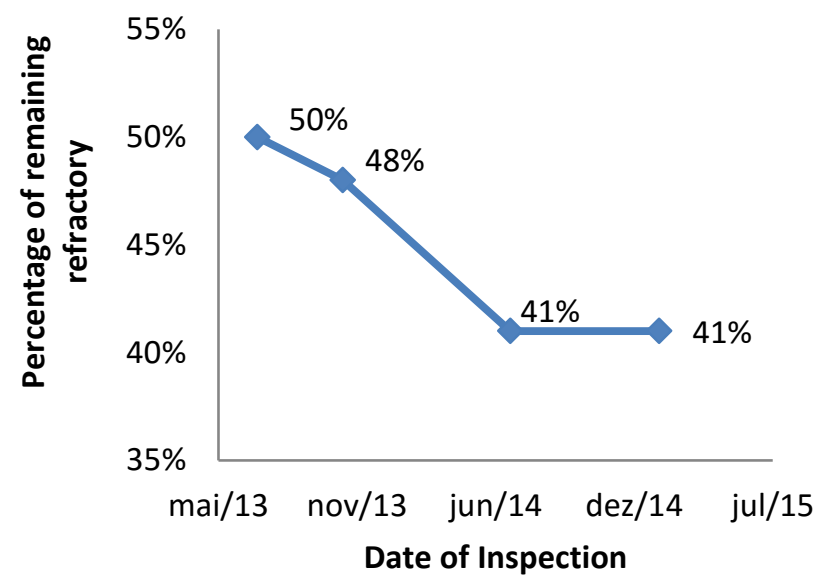

Figure 6. Blast furnace \#5 average refractory wear trend.

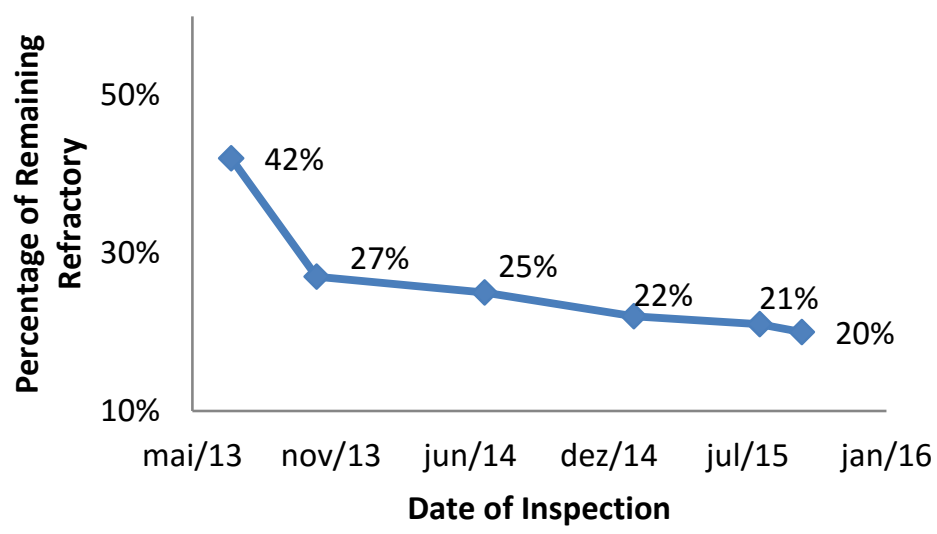

Figure 7. Blast furnace \#6 average refractory wear trend.

After the start of AU-E testing in 2013, the average refractory wear between May 2013 and July 2014 was 9\% for blast furnace \#5 and 17\% for blast furnace \#6. From July 2014 until February 2015 the thickness of hearth refractory lining of blast furnace \#5 was stabilized at average remaining refractory of $41 \%$ of original thickness. Stabilization of refractory wear at blast furnace \#6 started in November 2013 with regular addition of shungite and titania. Note that the effects of shungite addition on accretion formation were first discovered at BF \#6 in 2002 - 2004 during the trials for partial coke substitution by shungite. Similar to blast furnace \#7, the coke quality at blast furnace \#6 was also improved starting from 2013. For blast furnace \#6 the average rate of refractory wear has varied between the last four periods of measurement, ranging from $0.5 \% /$ month to $0.17 \% /$ month.

\section{WARNING TEMPERATURE ESTIMATION}

The combination of $\mathrm{AU}-\mathrm{E}$ results with temperature measurements by thermocouples (usually closest to the cold face of refractories) allows for an estimation of the 
warning temperature. This warning temperature indicates that the refractory lining has reached the minimum acceptable thickness, for example $30 \%$ of initial lining (including accretion). It is assumed that heat flux from hot metal to the frozen accretion and through the wall remains the same and that the conductivity coefficient is a weighted average value of the conductivity of refractories and accretion.

The method of estimation for the warning temperature is presented in Figure. Case 1 is the current scenario and Case 2 is the predicting case with $30 \%$ of remaining lining thickness. Here $S_{n}$ is the location of thermocouples from the brick-stave interface; $S$ is the current remaining thickness; S30 is the 30\% of remaining thickness; $T$ is the thermocouple temperatures; $\mathrm{T}^{1}{ }^{\prime}$ is the temperature of the first thermocouple when $30 \%$ remaining lining has reached; TBS is the temperature of brick-stave interface and $11500 \mathrm{C}$ is the hot metal solidification temperature.

The final equation for warning temperature estimation is as follows:

$$
\mathrm{T}^{\prime}{ }^{\prime}=1150-\left[(1150-\mathrm{T} 1)^{*}(\mathrm{~S} 30-\mathrm{S} 1)\right] /(\mathrm{S}-\mathrm{S} 1)
$$

The results of the November 2013 AU-E inspection and thermocouples readings were used to estimate the results presented in

Table. The AU-E measured refractory thickness closest to the thermocouple was used in calculations. Based on the literature, it was assumed that thermocouple error is also in the range of $20-25 \%$. Naturally, all of this contributes to calculation errors.

Table shows that the remaining refractory thickness estimation by heat flux and the remaining refractory thickness measured by $A U-E$ differed by $3-15 \%$. The estimated T1' (when remaining refractory is $30 \%$ ) is at least twice as much as the current measured T1 at the corresponding points. This indicated that this area of the furnace was still safe to operate.
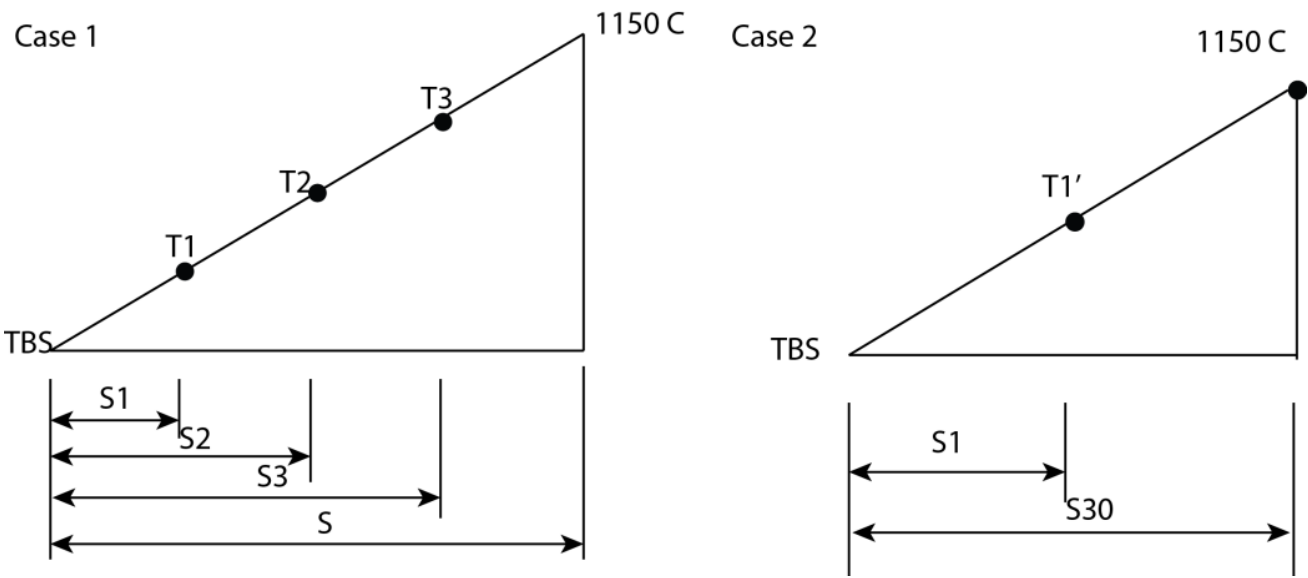

Figure 8. Schematics for warning temperature estimate

Table 2. Example of warning temperature estimation

\begin{tabular}{|c|c|c|c|c|c|c|c|}
\hline \multirow[b]{2}{*}{$\mathrm{T} 1\left({ }^{0} \mathrm{C}\right)$} & \multirow[b]{2}{*}{$\mathrm{T} 2\left({ }^{\circ} \mathrm{C}\right)$} & \multirow[b]{2}{*}{$\mathrm{T} 3\left({ }^{\circ} \mathrm{C}\right)$} & \multicolumn{2}{|c|}{ Reference point } & \multirow{2}{*}{$\begin{array}{l}\text { Thermal estimate of } \\
\text { remaining refractory, } \\
\mathrm{mm}\end{array}$} & \multirow{2}{*}{$\begin{array}{l}\text { AU-E Measured } \\
\text { Remaining } \\
\text { Refractory (mm) }\end{array}$} & \multirow[b]{2}{*}{$\mathrm{T} 11^{\circ}\left({ }^{0} \mathrm{C}\right)$} \\
\hline & & & $\begin{array}{l}\text { Vertical } \\
\text { Cross-Section }\end{array}$ & Point & & & \\
\hline 331 & 528 & 781 & 11 & 9 & 669 & 710 & 681 \\
\hline 271 & 433 & 572 & 2 & 9 & 964 & 820 & 729 \\
\hline 327 & 512 & - & 10 & 12 & 817 & 840 & 649 \\
\hline
\end{tabular}




\section{CONCLUSIONS}

Intensive operation of the blast furnace requires careful control of the hearth refractory lining conditions. The case studies at NLMK showed that AU-E is a reliable technology of estimation of the thickness of refractories, accretion and location of cracks or anomaly within the accuracy of $4-7 \%$. The application of AU-E technology for NLMK blast furnaces revealed conditions of the refractory lining, formation of accretion and the regions of highest wear. This allowed NLMK and Hatch to develop and implement preventive measures to prolong furnace campaign and continue safe furnace operation. These measures include (but are not limited to) the addition of shungite, titania materials, stave washing and utilization of higher quality coke. All of these allow NLMK to carefully control blast furnace conditions while maintaining their intensive operation.

\section{Acknowledgments}

With special thanks to our colleagues from Novo-Lipetsk Metallurgical Combine, Russia and Hatch, Canada for their valuable contribution in this work and preparation of this paper.

\section{REFERENCES}

1 Sadri, A. (2006). Systems, methods and apparatus for non-disruptive and nondestructive inspection of metallurgical furnaces and similar vessels: patent application publication: US 20060186585.

2 Sansalone, M.J., \& Streett W.B. (1997). Impact-Echo: Nondestructive Evaluation of Concrete and Masonry, Bullbrier Press, Ithaca, NY. p. 339.

3 Sadri, A. (2005, August). Non-destructive determination of refractory and build-up thickness in operating furnaces using an acousto ultrasonic reflection technique. Proceedings of the Materials Degradation: Innovation, Inspection, Control and Rehabilitation Symposium, COM2005. Calgary, Alberta, Canada.

4 Sadri, A., Gordon, I., \& Rampersad, A. (2007, May). Acousto ultrasonic-echo (AU-E): A non-destructive testing technique for blast furnace hearth refractory condition monitoring., AdMet 2007, Proceedings of International Conference Advances in Metallurgical Processes and Materials, Vol. 2. 77-85, Dnipropetrovsk, Ukraine.

5 Kurunov, I., Lyapin, S., Titov. V., Loginov, V. and Polyakov N. (2006, November). New technological solutions for the lining protection of the blast furnace hearth. Proceedings of the 4th International congress on Science and Technology of Ironmaking (ICSTI'06), Osaka, Japan, November 26-30, 2006, p.p.543-546. 